\title{
ON THE BINOMIAL TRANSFORMS OF THE HORADAM QUATERNION SEQUENCES
}

\author{
Faruk Kaplan ${ }^{1}$ and Arzu Özkoç Öztürk ${ }^{2}$ \\ ${ }^{1}$ Duzce University \\ ${ }^{2}$ Düzce Üniversitesi
}

December 8, 2020

\begin{abstract}
The main object of the present paper is to consider the binomial transforms for Horadam quaternion sequences. We gave new formulas for recurrence relation, generating function, Binet formula and some basic identities for the binomial sequence of Horadam quaternions. Working with Horadam quaternions, we have found the most general formula that includes all binomial transforms with recurrence relation from the second order. In the last part, we determined the recurrence relation for this new type of quaternion by working with the iterated binomial transform, which is a dierent type of binomial transform.
\end{abstract}

\section{Hosted file}

ON THE BINOMIAL TRANSFORMS OF THE HORADAM QUATERN \selectlanguage\{polish\}İ $\backslash$ selectlanguage\{english\}ON SEQ available at https://authorea.com/users/381828/articles/497729-on-the-binomial-transformsof-the-horadam-quaternion-sequences

\section{Hosted file}

ON THE BINOMIAL TRANSFORMS OF THE HORADAM QUATERN \selectlanguage\{polish\}İ $\backslash$ selectlanguage\{english\}ON SEQ available at https://authorea.com/users/381828/articles/497729-on-the-binomial-transformsof-the-horadam-quaternion-sequences 